\title{
Promoting positive community relations: what can RE learn from social psychology and the Shared Space project?
}

\author{
Amanda Williams ${ }^{1}$ \\ Shelley McKeown ${ }^{1}$ \\ Janet Orchard ${ }^{1}$ \\ Kathryn Wright ${ }^{2}$ \\ ${ }^{1}$ School of Education, University of Bristol, Bristol, UK \\ ${ }^{2}$ Diocese of Norwich, Norwich, UK
}

Corresponding author

Amanda Williams: School of Education, University of Bristol, 35 Berkley Square

Bristol, BS8 1JA. Email: a.williams@ bristol.ac.uk Telephone: 01173314497

Co-Authors

Shelley McKeown: School of Education, University of Bristol, 35 Berkley Square

Bristol, BS8 1JA. Email: s.mckeownjones@bristol.ac.uk Telephone: 01173314389

Janet Orchard: School of Education, University of Bristol, 35 Berkley Square, Bristol, BS8

1JA. Email: janet.orchard@bristol.ac.uk Telephone: +44 (0)117331 4306

Kathryn Wright: Diocesan House, 109, Dereham Road, Easton, Norwich. NR9 5ES Email: Kathryn.wright@ dioceseofnorwich.org Telephone: 01954261457

Acknowledgements

We would like to express our thanks to the National Association for Teachers of Religious Education for supporting our research ideas and to our funders (the University of Bristol's 
ESRC Impact Acceleration Account and Westhill Trust Standard Grant) for providing the financial support to explore the potential impact of our research with RE teachers.

Author biographies

Amanda Williams ( $\mathrm{PhD}$ York University, Canada) is a lecturer in psychology at University of Bristol's School of Education. Her research adopts a multi-method approach to examining intergroup processes. She has published journal articles focused on the influence of context on children's and adults' (implicit) biases and stereotypes.

Shelley McKeown (PhD: Ulster) is a senior lecturer in social psychology at the University of Bristol's School of Education. Her research focuses on understanding and improving intergroup relations in diverse and conflict settings. She has published a number of journal articles focusing on intergroup contact theory.

Janet Orchard (PhD Institute of Education, University of London) is a Senior Lecturer in Religious and Philosophy of Education at the University of Bristol's School of Education. Her research focuses on teachers and their professional understanding, with a particular interest in ethical deliberation and dialogue in diverse settings. She has published a number of journal articles on these themes.

Kathryn Wright: (PhD: University of East Anglia) is an independent RE Adviser working primarily for the Diocese of Norwich and Culham St Gabriel's Trust. Her doctoral research explored the purpose of RE and pedagogical approaches to RE in Church of England schools. She is a co-opted member of the NATRE executive and is an RE Council representative. 


\section{Promoting positive community relations: what can RE learn from social psychology and the Shared Space project?}

In this paper we considered the relevance of specific claims that 'multi-faith' approaches to Religious Education (RE) play a role in promoting good community relations. In doing so, we adopted a social-psychological perspective where engaging in positive and meaningful interactions with diverse others reduces prejudice. Survey responses from $92 \mathrm{RE}$ teachers across the UK were examined to determine the extent to which strategies for promoting positive community relations were embedded within classroom practice. We next examined whether teachers intuitively used social psychological theory - namely the contact hypothesis - to promote positive communities in their classrooms. Results demonstrated that the majority of surveyed RE practitioners perceived community relations to be a core aim of RE and that contact theory was applicable to their practice. Teachers reported examples of how they embed both contact theory and RE in their classrooms but not all of these aligned with social psychological theory. Findings suggest that successful practice in RE may be further developed by integrating theoretical principles of the contact hypothesis. Implications and future directions will be discussed.

Keywords: community relations; religious education; intergroup contact theory 
Promoting positive community relations: what can RE learn from social psychology and the Shared Space project?

It has sometimes been held that merely by assembling people without regard for race, color, religion or national origin, we can thereby destroy stereotypes and develop friendly attitudes. The case is not so simple. (Allport, 1954, 261)

Racial and ethnic diversity within the United Kingdom (UK) is a lived reality. Approximately $19 \%$ of the UK resident population identify as racial/ethnic minorities (ONS, 2015), and as many as $27 \%$ of pupils in state funded secondary schools define themselves as of minority ethnic origin (DfE, 2015). Whilst exposure to new cultures can help enrichen life experiences, it can also be associated with tension and discrimination. For example, $25 \%$ of the UK population believe that the level of prejudice and discrimination they experience has gone up since 2000 and in 2013/14, $84 \%$ of hate crimes recorded by the police were race related (Creese and Lader, 2014). Moreover, post Brexit, tensions and divisions between ethnic groups have become increasingly evident (Harker, 2016); understanding how to promote community relations in diverse settings is critical.

In this light, schools and teachers have come under increasing pressure on two fronts. First, they have been required to adapt their subject specific practices to the demands of addressing an ever more complex range of religious, ethnic and racial backgrounds. Second, they have been required to take a positive and active role on behalf of wider society in promoting community relations; Religious Education (RE), as a compulsory subject on the school curriculum in England, is often defended by its supporters as being "uniquely placed to help children and young people develop the knowledge and skills they need to play their part in today's society and tomorrow's world" (All Party Parliamentary Group [APPG], 2014, 1). However, understanding the extent to which RE can promote community relations, and 
whether teachers see this role as integral to RE, has yet received little empirical investigation (Chater and Erriker 2013; Orchard 2015).

This paper presents findings from the Shared Space Project which investigated how RE practitioners might intuitively apply social psychological theory to promote community relations in the RE classroom. We focused on practitioners' perceptions of the role of community relations in RE and the extent to which they embed this in their classroom practice, distinctively using social psychological theory to examine the potential success of teaching activities. In particular, we examined whether practitioners considered one specific theory - the contact hypothesis (Allport, 1954) - as useful and the extent to which they might already embed this into their practice. The Shared Space Project offers an initial response to Orchard's call (2015) for research that accounts for and explains, in pedagogical terms, RE's role in promoting community relations.

\section{Why Religious Education (RE)?}

As previously mentioned, one argument commonly used to defend Re's inclusion as a compulsory subject on the school curriculum in England is the claim that learning in RE can promote better community relations (Orchard, 2015). Learning about different religions in the world, it is assumed, will impact positively on attitudes that guide interactions with diverse others (Orchard, 2015). Between December 2013 and March 2014, an All Party Parliamentary Group (APPG) for RE sat for three sessions to hear how RE contributes to community cohesion, at which advisers, teachers, academics and faith representatives asserted the connection. Valuable personal experience and impressions were shared, yet still no compelling systematic evidence in support of the claim was offered (APPG, 2014). Further, an independent Commission on Religious Education (CoRE, 2017) concluded that RE contributes to community relations by providing a space to discuss difference (Jackson, 2014, 2015). 
The conclusion that RE can make positive contributions to community relations was based partly on pupils' statements made during evidence gathering sessions held in 2017. These statements highlighted the key difference that RE made for them, for example:

We learn to accept differences in each other as understanding breeds tolerance in our diverse communities. This allows us to create a safe environment that benefits everyone (Year 9 pupil, oral evidence submitted to the Commission in Birmingham, CoRE, 2017, 27);

[Studying RE] has helped me have more friends in school - there are other faiths in school and my best friend is a Muslim. We are connected because we've got to understand each other's faiths through RE. (Year 10 pupil, oral evidence submitted to the Commission in Manchester, CoRE, 2017, 26);

You learn to respect your peers. You learn about their religion, rights and responsibilities $-\ldots$ You won't then isolate them or bully them because of their faith. (Year 10 pupil, oral evidence submitted to the Commission in Manchester, CoRE, 2017, 27)

Yet still, rigorous empirical evidence to support the beneficial claims of RE in promoting community relations was not provided and the proposed link between multi-faith RE and community relations remained unsubstantiated (see Barnes, 2014, for a similar argument). It is worth pointing out that these examples were provided by secondary school pupils, as was the case in the REfor Real report (Dinham and Shaw, 2015) which also only referred to a small number of secondary school pupils. We propose that it is time to move beyond intuition to an empirical investigation of these matters and one which embraces practice across all phases.

We note that promoting better community relations should not be seen as the sole mission or responsibility of RE teaching. Tensions in social relations cannot be solely 
"reduced to religious causes" (Orchard, 2015, 43), incorporating as they do other significant factors, including ethnicity/race, culture, family, ability, social class and material wealth. RE would be severely diminished if it were to be reduced solely to this aim (Orchard, 2015). Rather, we believe, promoting community relations is a matter for all curriculum subjects, whole school processes, parents, carers and the wider community.

Nevertheless, the idea that people will get along better when they understand others' religious beliefs and practices is intuitive both in education and in general public opinion, particularly when issues seemingly caused by religious diversity make headline news. Addressing religious and cultural diversity would not be a priority of the Commission for Religious Education were it not in the interest of the subject to make this case forcefully. However, more effort is needed to systematically examine the role of community relations in RE. As Mark Chater has argued, while a 'causal link' between 'multi-faith RE' and 'better community relations' is widely assumed, whether or not in practice there is a link remains untested (Chater and Erricker, 2013, 37).

\section{Community Relations and Social Psychology}

Although other research traditions are well placed to provide insight into how to promote community relations, this project explores the potential contribution of social psychology to informing practice in RE and beyond. In particular, the sub-discipline of intergroup relations boasts a rich history of empirical and theoretical research examining how individuals from different groups interact with one another, and how we can alter conditions to facilitate positive intergroup interactions - that is how can we best promote positive interactions amongst diverse people. Research and theory in intergroup relations offers, we maintain, one useful lens through which to systematically examine intuitions of the positive impact well taught RE might have on positive community relations. 
For example, good RE is said to encourage students to think about and take the perspective of individuals from a wide range of religious, and to engage in discussion about religious difference and to challenge stereotypes associated with different religious communities (e.g., Jackson 2014). These are also hallmarks of social psychological interventions that have been successful in promoting positive intergroup relations. Research has demonstrated that encouraging individuals to take the perspective of diverse others can increase empathy, increase awareness of contextual effects for explaining inequalities, and strengthen the inclusion of other in self-concepts, thereby improving intergroup relations (e.g., Todd and Galinsky, 2014). Learning about others (e.g., Allport, 1954; Stephan and Stephan, 1984), challenging stereotypes and providing individuals with counter-stereotypical exemplars has similarly been shown to override existing group-level associations and reduce racial bias (e.g., Dasgupta and Greenwald, 2001; Gonzalez, Steele, and Baron, 2017; Lai et al., 2014).

In the early 1950s, intergroup interactions (that is interactions between those who are different from one another for example from different racial or religious groups) were atypical and often fraught with anxiety and discrimination (Allport, 1954). More recently, evidence of anxious behaviour and subtle discrimination has been observed when individuals interact with ethnically and religiously diverse others (e.g., Paolini, Hewstone, Cairns, and Voci, 2004; Toosi, Babbitt, Ambady, and Sommers, 2012). In these diverse interactions, social psychological research indicates that all parties bring subtle and overt anxiety, stereotypes, and prejudicial views that influence the success of the interaction. Hence, RE lessons may be ideally positioned to help students navigate the complex social interactions necessary to building positive relationships with their diverse peers. According to research in intergroup relations, it is reasonable to expect that positive community relations would be fostered by good practice in RE. 
Further research (both within social psychology and other fields) has examined other conditions under which intergroup relations can be improved in ways that might be relevant to RE. Successful strategies are varied, ranging from interventions that target the individuals to those that target the group. Individual-level interventions include computer-based tasks where individuals are trained to alter their approach motivations toward diverse others (Kawakami, Phills, Steele, and Dovidio, 2007) or encouraging individuals to take the perspective of others (Todd and Galinsky, 2014). Group-level interventions include reading a classroom of children stories that encourage them to value diversity (McKeown, Williams, and Pauker, 2017) or that alter the ideology of the classroom/school, specifically changing from a colourblind approach where differences are minimized to a multicultural or polycultural ideology that celebrates differences (Rosenthal and Levy, 2010). Those interventions can be focused on providing good examples, such as the teacher or peers modelling appropriate behaviour (Liebkind and McAlister, 1999) or target individuals by encouraging them to extend the notion of who constitutes an ingroup member through exploring intergroup commonality (e.g., Gaertner, Rust, Dovidio, Bachman, and Anastasio, 1994). As can be seen, there are a myriad of approaches to improving community relations supported by empirical research conducted within social psychology.

As testing the full range of possibilities was not possible within the scope and scale of one pilot project, the Shared Space project identified one specific intervention strategy judged particularly relevant; Gordon Allport's contact hypothesis (1954). According to Allport, bringing individuals from conflicted groups together under favourable conditions can reduce prejudice and improve intergroup relations. These favourable conditions for contact include: equal status among those involved (within the contact situation), cooperation between groups, working towards a common goal, in conditions where the contact is socially and institutionally supported. Although not without its limitations (a point we return to in the 
discussion), we focus on the contact hypothesis because, as mentioned above, it maps directly to good RE practice. More importantly, this strategy can be easily adapted to classroom practice and the success of this for promoting positive relations amongst diverse groups has been consistently replicated across a wide age range of participants (see Pettigrew and Tropp, 2006, for a review).

Pettigrew and Tropp (2006) reviewed over 500 research papers and found that with consistency, meeting the four conditions outlined by the contact hypothesis was effective in reducing prejudice toward a wide range of outgroups (i.e., race/ethnicity, religion, etc.). Further, research indicates that reductions in prejudice is transferred from individual targets to the entire outgroup. Thus these results provide conclusive evidence that the contact hypothesis is a valid method for improving intergroup relations across a variety of contexts and that effects should extend beyond the classroom (Pettigrew and Tropp, 2006). Meeting the four conditions of the contact hypothesis has been shown to promote the meaningful discussion of difference (McKeown, Cairns, Stringer, and Rae, 2012) and to reduce anxiety and perceived threat, and increase empathy when interacting with diverse others (Pettigrew and Tropp, 2008). Because of the conceptual overlap between learning about others in multifaith RE, positive community relations and contact theory, we believe contact theory can provide practical results for the RE classroom.

At its core, the contact hypothesis offers insight into the types of interaction that enable a reduction in tension, prejudice and/or anxiety between members of different groups. But, in order for contact to have these beneficial outcomes, there is a need to move beyond simply bringing groups together and instead practitioners need to ensure that meaningful contact occurs. When diverse individuals merely co-exist in the same space, individuals tend to interact with those who are similar to themselves. Even reception and Year 1 aged children tend to sit next to same-race peers in the lunch room (McKeown, Williams, and Pauker, 
2017). Examples of such self-segregated behaviours can be observed in everyday spaces including beaches (Dixon and Durrheim, 2003), nightclubs (Tredoux and Dixon, 2009), schools (McKeown, Stringer and Cairns, 2015) and universities (Orr, McKeown, Stringer and Cairns, 2012). It is therefore vital to understand how contact can be best harnessed in settings where individuals from different backgrounds come together naturally.

Perhaps unsurprisingly, the contact hypothesis has been applied in educational settings across the UK and beyond. In Northern Ireland, for example, integrated education and shared education policies are based upon the premises of contact theory (Donnelly and Hughes, 2006; Hughes and Loader, 2015). A good example of the contact hypothesis in practice is found in the Linking Network (http://thelinkingnetwork.org.uk/), a Bradford-based charity which directly links schools from different communities, as well as trains teachers in contact principles in order to inform their planning and future work in the classroom. The work of this charity shows that when teachers are more aware of power relationships in the classroom, they are better able to understand some of the root causes of poor social relations. Another example, presented in more detail in a Teachers' Toolkit developed through the Shared Space Project (detailed below), is of the Corrymeela community. This was established in Belfast in 1965 to address rising alienation and violence between Catholic and Protestant groups. Today Corrymeela provides a space for dialogue, questioning and mutual learning. Over the years, this initiative has found that in order to bridge divisions, difficult topics must not be avoided when members of different groups come together. Insights from organisations like the Linking Network or Corrymeela give the teacher confidence when developing teaching materials to meet contact conditions in the classroom. Furthermore, it is plausible that greater levels of religious literacy promoted through RE lessons might contribute positively to community relations in enabling a more knowledgeable starting point for contact between members of different groups. In the following section we present the 
Shared Space Project which we have used as a starting point to examine the role of RE in promoting positive community relations.

\section{The Shared Space Project}

Social psychologists from the University of Bristol collaborated with RE researchers and the National Association of Teachers of RE (NATRE) to explore how relevant insights from a field related to but outside RE might inform the potential link between RE and community relations; with a view to providing practical ways forward for interested teachers, based on their findings. This collaboration formed the Shared Space Project (see https://www.natre.org.uk/about-natre/projects/the-shared-space-project/ for more information).

In this project, we considered how RE lessons might improve the quality of interaction or 'positive contact' between diverse individuals, that is individuals from different ethnic, religious or racial backgrounds. We acknowledge that while RE lessons on their own may not be sufficient to refute stereotypes or develop friendly attitudes, particularly where deep-rooted and bigoted prejudices are concerned, nevertheless there are distinctive ways in which positive contact could be fostered within RE in order to promote better intergroup relations. Specifically, we examined the utility of the contact hypothesis (Allport, 1954) for the RE classroom. We explored RE practitioners' perceptions of the role of community relations in RE and ways in which the contact hypothesis may be already embedded in their practice. The ultimate goal of this project was to create a teacher toolkit that would assist teachers in applying the contact hypothesis to their practice. A more detailed analysis of the findings from the Shared Space Project is available from the authors.

\section{Summary of Findings from the Shared Space Project}


The project employed a mixed methods approach, combining both quantitative and qualitative forms of data collection. Researchers attended a series of RE teacher meetings and conferences during 2016-17 to introduce and discuss contact theory and to recruit participants to an on-line survey of RE practitioners in England. The survey sample comprised $95 \mathrm{RE}$ practitioners $^{1}$ (57 females, 18 males, 2 did not identify; $M_{\text {age }}=41.47, S D=11.46$ ) with a range of teaching experience $\left(M_{\text {years }}=15.47, S D=10.44\right)$ across different levels of provision (16 primary teachers, 51 secondary teachers, 10 other). In a series of questions, practitioners were asked to indicate their agreement with statements concerning the relevance of community relations and the contact hypothesis to $\mathrm{RE}(1=$ strongly disagree to $6=$ strongly agree), the extent to which they embed community relations and the contact hypothesis to their practice $(1=$ Never to $6=$ Always $)$, and to provide up to 3 examples of their practice (open-ended responses). Open ended responses were communally coded on a variety of themes, all discrepancies were discussed and a consensus reached between the researchers.

The majority of teachers agreed that community relations was a core aim of RE (96\% of respondents) and indicated that they embed community relations in their practice, at least occasionally (94\%). Using a social psychological lens to evaluate responses, $67 \%$ of examples provided by practitioners were determined as being effective techniques for embedding community relations when using criteria from the social psychological literature. Discussion/dialogue about difference was most frequently reported (39\% of examples), followed by visits with diverse others (24\%), strategies that promoted equality/diversity (21\%), learning about different cultures/faiths (11\%), addressing inequality from a Christian perspective (5\%), and discussion/dialogue about similarities (1\%). Examples are provided in Table 1.

\footnotetext{
${ }^{1}$ Fifteen participants did not provide demographic information.
} 
Further analysis demonstrated that the majority (95\%) of respondents agreed that the contact hypothesis was applicable - and in fact was being applied (89\%) - to classroom practice. When coding the examples given by practitioners, to be identified as representing the principles of the contact hypothesis (Allport, 1954) participants had to explicitly identify a component of direct contact where students interacted with a racially/ethnically diverse individual (e.g., "seating plan to get children to sit beside diverse peers"). Of the examples provided only $23 \%$ were found to meet these criteria. Examples of RE teacher practice were categorized as: Encounter (33\% of examples were approaches that expose pupils to diverse others, but do not necessarily promote meaningful discussions); Conversation (25\% were approaches that develop discussion and listening skills, but may occur in the absence of diverse others); and Interaction (23\% were approaches that exemplify contact theory by promoting both exposure and meaningful discussion).

Teachers provide examples of encounters most frequently but evidence of encouraging structured interaction in practice was less common. Teachers also provided examples of strategies that might be successful in promoting community relations, but did not meet the principles of the contact hypothesis (17\% of examples). Examples are provided in Table 2.

\section{Discussion}

The Shared Space initiative brought together researchers and teachers to examine the role of RE in promoting community relations. Its goal was to examine practitioners' perceptions of the role of community relations in RE and the extent to which they embed this in their classroom practice. It examined whether the contact hypothesis (Allport, 1954) was being applied by practitioners to promote community relations in the RE classroom. Although a topic of debate within the wider RE community (Orchard, 2015), practitioners who completed our survey overwhelmingly agreed that promoting community relations is a 
core aim of RE. In order to begin to move beyond the intuition that simply learning about others will improve community relations, a small scale empirical investigation was conducted where a social psychological lens was applied to examine the effectiveness of classroom practice.

Findings demonstrate that practitioners do embed some strategies in their practice that might promote community relations. From the examples given, we saw evidence of theoretically supported practice, particularly around discussing difference, visiting diverse others, and adopting strategies that promote equality/diversity. We argue that such examples would be effective in promoting community relations as they map on to interventions demonstrated to improve intergroup relations within the social psychological literature. For example, discussions of differences often promote perspective taking, which has been demonstrated to reduce prejudice and stereotyping by increasing empathy toward and awareness of others (Todd and Galinsky, 2014). Visiting diverse others - particularly when meaningful interactions occur - can meet the principles of contact hypothesis which have been demonstrated to reduce prejudice by reducing intergroup anxiety and improve empathy toward diverse others (Pettigrew and Tropp, 2008). Finally, promoting diversity can alter the ideological structure of the classroom by moving from a colourblind approach (differences are minimized) to multicultural/polycultural ideology (differences are noted and celebrated). This serves to increase knowledge of, respect for and attention to the valued identities of marginalized groups (Rosenthal and Levy, 2010). Together these findings suggest that research in the area of intergroup relations lends itself nicely to community relations in RE and is being intuitively applied by practitioners. A more systematic investigation of what social psychology can offer the RE classroom is clearly an avenue for future fruitful research.

We were also interested in the extent to which the contact hypothesis was embedded in practice. We focused on this theory because of the conceptual overlap with good practice 
in RE (i.e., focus on perspective taking of individuals from different faiths, discussing difference, and challenging stereotypes; e.g., Jackson, 2014), the strong empirical evidence of the replicability of effects (Pettigrew and Tropp, 2006), and the ease of application in classroom settings across the globe (Donnelly and Hughes, 2006) using a range of techniques (e.g., Aronson, 2002; Blaylock and Hughes, 2013). The majority of practitioners perceived the contact hypothesis to be relevant to, and embedded within, their practice. Examples given revealed three different ways contact was being applied in practice including (1) approaches that expose pupils to diverse others, but do not necessarily promote meaningful discussions, (2) approaches that develop discussion and listening skills, but perhaps in the absence of diverse others, and (3) approaches that exemplify contact theory by promoting both exposure and meaningful discussion. The latter strategy would be most effective in promoting positive community relations in the RE classroom, and beyond (Allport, 1954; Pettigrew and Tropp, 2006).

We observed, however, that not all practitioners were applying the principles of the contact hypothesis to their classroom. Respondents also provided examples of practice that were not relevant to contact theory but might nevertheless be effective in promoting community relations. For example, challenging stereotypes, encouraging perspective taking, and adopting a multicultural/polycultural ideology toward diversity are some strategies that were reported. That teachers are intuitively using a variety of strategies to promote community relations highlights the potential of engaging teachers in dialogue around theory informed practice.

Together, these findings offer support for the role that RE can play in community relations and there is clear evidence of good practice within the RE community. It is important to recognise, however, that promoting community relations is not the sole responsibility of RE; it should be a focus of other subjects and the whole school as well. 
Nevertheless, our findings offer initial evidence that RE may contribute to warmer community relations through embedding practices that are empirically supported in other research focused on improving intergroup relations.

\section{Implications}

We believe that our findings have a number of implications for RE pedagogy. Our results suggest that RE practitioners could be well-placed to promote the contact hypothesis in the classroom if conversation and encounter are developed alongside other opportunities for deliberate, positive interactions. Developing the capacity to talk about religious, ideological and cultural differences in ways which go beyond the superficial, and possibly into painful and difficult territory, is a potential distinctive strength of $\mathrm{RE}$ as an academic subject (Jackson, 2014) Framed by the three categories (encounter, conversation and interaction), we have created a toolkit focused on the contact hypothesis for teachers, available on the National Association for Teachers of RE website (see https://www.natre.org.uk/uploads/Additional\%20Documents/Teachers\%20toolkit\%20FINAL .pdf), outlining practical and age-appropriate teaching ideas to offer teachers a sense of how far their current work promotes contact and how they can strengthen it. We hope future joint research will help us to co-produce empirical investigations of our toolkit.

\section{Limitations and Future Directions}

Whilst our work has a number of key strengths, it is important to recognise that we surveyed a relatively small sample of RE teachers. We also recognise that there may limitations to the contact hypothesis, such as times when contact does not work or has negative consequences such as increase perceived differences and result in negative attitudes (McKeown and Dixon, 2017). Practitioners are cautioned against a cookie-cutter application of the contact hypothesis, and are strongly advised to ensure the four conditions of the contact 
hypothesis - equal status of those involved, cooperation between groups, working toward a common goal, and providing social support for contact -are met (e.g., Al Ramiah and Hewstone, 2013). We therefore recommend that teachers apply theory with caution and refer to established research when doing this. This in turn highlights the need for bridging the potential gap between (educational) research and practice. The research to practice gap is a broader issue addressed by the BERA-RSA Inquiry into the use of educational research by the teaching profession (BERA-RSA 2014) but initiatives within the discipline of RE are also under development (e.g., the REsearch for RE project by the Culham St Gabriel's Trust: http://www.cstg.org.uk/how-we-help/research-for-re). When undertaken in the domain of RE, using research informed practice will help to substantiate the claimed link between multifaith RE and community relations. 


\section{References}

Allport, G. 1954. The Nature of Prejudice

All Party Parliamentary Group on RE. 2014. RE and Good Community Relations. Available from:

http://oldrec.commissiononre.org.uk/media/file/APPG_report_RE_and_good_communi ty re.pdf

Al Ramiah, A., and Hewstone, M. 2013. Intergroup contact as a tool for reducing, resolving, and preventing intergroup conflict: evidence, limitations, and potential. American Psychologist, 68, 527.

BERA-RSA. 2014. Research and the Teaching Profession: Building the Capacity for a SelfImproving Education System. Available from: https://www.bera.ac.uk/wpcontent/uploads/2013/12/BERA-RSA-Research-Teaching-Profession-FULL-REPORTfor-web.pdf?noredirect=1

Aronson, E. 2002. Building empathy, compassion, and achievement in the jigsaw classroom. Improving academic achievement: Impact of psychological factors on education, 209-225.

Barnes, L. P. 2014. Education, Religion and diversity: Developing a New Model of Religious Education, Routledge, Abingdon, Oxon

Blaylock, D., and Hughes, J. 2013. Shared education initiatives in Northern Ireland: A model for effective intergroup contact in divided jurisdictions. Studies in Ethnicity and Nationalism, 13, 477-487.

Chater, M. and Erricker, C. 2013. Does Religious Education Have a Future? Routledge, Abingdon, Oxfordshire

Commission on Religious Education [CoRE]. 2017. Interim report: Religious education for all. Available from: http://www.commissiononre.org.uk/wp- 
content/uploads/2017/09/Commission-on-Religious-Education-Interim-Report-

2017.pdf

Creese, B. and Lader, D. 2014. Hate Crimes, England and Wales, 2013/14. Home office statistical bulletin. Available from: http://www.reportit.org.uk/files/home_office_hate_crime_data_201314.pdf

Dasgupta, N., and Greenwald, A. G. 2001. On the malleability of automatic attitudes: combating automatic prejudice with images of admired and disliked individuals. Journal of personality and social psychology, 81, 800.

Department for Education [DfE]. 2015. Schools, pupils and their characteristics. Available from:

https://www.gov.uk/government/uploads/system/uploads/attachment_data/file/433680/ SFR16_2015_Main_Text.pdf

Dinham, A., and Shaw, M. 2015. RE for Real: The Future of Teaching and Learning about Religion and Belief. London: Goldsmiths University Faith and Society Unit.

Dixon, J., and Durrheim, K. 2003. Contact and the ecology of racial division: Some varieties of informal segregation. British journal of social psychology, 42, 1-23.

Donnelly, C., and Hughes, J. 2006. Contact, culture and context: Evidence from mixed faith schools in Northern Ireland and Israel. Comparative education, 42, 493-516.

Gaertner, S. L., Rust, M. C., Dovidio, J. F., Bachman, B. A., and Anastasio, P. A. 1994. The contact hypothesis: The role of a common ingroup identity on reducing intergroup bias. Small group research, 25, 224-249.

Gonzalez, A. M., Steele, J. R., and Baron, A. S. 2017. Reducing children's implicit racial bias through exposure to positive out-group exemplars. Child development, 88, 123-130.

Harker, J. 2016, June 24. After this leave vote it's worrying to be an ethnic minority Briton. The Guardian. Available from: 
https://www.theguardian.com/commentisfree/2016/jun/24/intolerance-ethnic-minoritypolesuk

Hughes, J., and Loader, R. 2015. 'Plugging the gap': shared education and the promotion of community relations through schools in Northern Ireland. British Educational Research Journal, 41, 1142-1155.

Jackson, R. 2014. Religion, Education, Dialogue and Conflict: Perspectives on Religious Education. Routledge.

Jackson, R. 2015. Inclusive study of religions and other worldviews in publicly-funded schools in democratic societies. In K. Stoeckl (Ed.) The Future of Religious Education in Europe (pp. 7-18). European University Institute.

Jivraj, S. and Simpson, L. 2015. How has ethnic diversity grown? In S. Jivraj and L. Simpson (Eds.) Ethnic identity and inequalities in Britain (pp. 19-32). Policy Press: Bristol, UK.

Kawakami, K., Phills, C. E., Steele, J. R., and Dovidio, J. F. 2007. (Close) distance makes the heart grow fonder: Improving implicit racial attitudes and interracial interactions through approach behaviors. Journal of personality and social psychology, 92, 957

Lai, C. K., Marini, M., Lehr, S. A., Cerruti, C., Shin, J. E. L., Joy-Gaba, J. A., ... and Frazier, R. S. 2014. Reducing implicit racial preferences: I. A comparative investigation of 17 interventions. Journal of Experimental Psychology: General, 143, 1765.

Liebkind, K., and McAlister, A. L. 1999. Extended contact through peer modelling to promote tolerance in Finland. European Journal of Social Psychology, 29, 765-780.

McKeown, S., Cairns, E., Stringer, M., and Rae, G. 2012. Micro-ecological behaviour and intergroup contact. The Journal of social psychology, 152, 340-358.

McKeown, S. and Dixon, J. 2017. The 'contact hypothesis': Critical reflections and future directions. Social and Personality Psychology Compass, 11. 
McKeown, S., Stringer, M., and Cairns, E. 2016. Classroom segregation: where do students sit and how is this related to group relations?. British Educational Research Journal, 42, 40-55.

McKeown, S., Williams, A., and Pauker, K. 2017. Stories that move them: Changing children's behaviour toward diverse peers. Journal of Applied Community Social Psychology, 27, 381-387.

Office for National Statistics [ONS]. 2015. 2011 Census Analysis: Ethnicity and Religion of the Non-UK Born Population in England and Wales. Available from: http://www.ons.gov.uk/ons/dcp171776_407038.pdf

Orchard, J. 2015. 'Does Religious Education Promote Good Community Relations?' in Journal of Beliefs and Values, 36, 40- 53

Orr, R., McKeown, S., Cairns, E., and Stringer, M. 2012. Examining non-racial segregation: A micro-ecological approach. British Journal of Social Psychology, 51, 717-723.

Paolini, S., Hewstone, M., Cairns, E., and Voci, A. 2004. Effects of direct and indirect crossgroup friendships on judgments of Catholics and Protestants in Northern Ireland: The mediating role of an anxiety-reduction mechanism. Personality and Social Psychology Bulletin, 30, 770-786.

Pettigrew, T. F., and Tropp, L. R. 2006. A meta-analytic test of intergroup contact theory. Journal of personality and social psychology, 90, 751.

Pettigrew, T. F., and Tropp, L. R. 2008. How does intergroup contact reduce prejudice? Meta-analytic tests of three mediators. European Journal of Social Psychology, 38, 922-934.

Rosenthal, L., and Levy, S. R. 2010. The colorblind, multicultural, and polycultural ideological approaches to improving intergroup attitudes and relations. Social Issues and Policy Review, 4, 215-246. 
Stephan, W. G., and Stephan, C. W. 1984. The role of ignorance in intergroup relations. In Groups in contact (pp. 229-255).

Todd, A. R., and Galinsky, A. D. 2014. Perspective-taking as a strategy for improving intergroup relations: Evidence, mechanisms, and qualifications. Social and Personality Psychology Compass, 8, 374-387.

Toosi, N. R., Babbitt, L. G., Ambady, N., and Sommers, S. R. 2012. Dyadic interracial interactions: A meta-analysis. Psychological Bulletin, 138, 1.

Tredoux, C.G., and Dixon, J.A. 2009. Mapping the multiple contexts of racial isolation: The case of Long Street, Cape Town. Urban Studies, 46, 761-777. 
TABLE 1. Researcher Identified themes for how community relations is embedded in practice, practitioner examples, and correspondence to research and theory in intergroup relations.

\begin{tabular}{|c|c|c|}
\hline Researcher-Identified Themes & Practitioner-provided Example & $\begin{array}{l}\text { Correspondence to Intergroup } \\
\text { Relations Research and Theory }\end{array}$ \\
\hline \multirow{2}{*}{$\begin{array}{l}\text { Discussion/Dialogue about } \\
\text { Difference }\end{array}$} & "Open discussion is welcome to address misconceptions" & Challenge Stereotypes \\
\hline & "Discussing tolerance, acceptance and celebrating differences" & $\begin{array}{l}\text { Multicultural/Polycultural } \\
\text { ideology }\end{array}$ \\
\hline \multirow[t]{2}{*}{ Visits with Diverse Others } & $\begin{array}{l}\text { "Visited the local Synagogue and Mosque to enable the children to get to know } \\
\text { their neighbours and see what life was like for those living out a different faith" }\end{array}$ & Meaningful Contact (Allport) \\
\hline & $\begin{array}{l}\text { "Taking children on trips to engage with people of faith to appreciate "what } \\
\text { makes them tick' and how faith affect their lives" }\end{array}$ & Meaningful Contact \\
\hline \multirow{2}{*}{$\begin{array}{l}\text { Strategies to promote } \\
\text { Equality/Diversity }\end{array}$} & "Providing stereotype-busting examples" & Challenge Stereotypes \\
\hline & $\begin{array}{l}\text { "I challenge pupils to observe, understand and welcome the benefits of living in a } \\
\text { multi-religious society" }\end{array}$ & $\begin{array}{l}\text { Multicultural/Polycultural } \\
\text { ideology }\end{array}$ \\
\hline \multirow{2}{*}{$\begin{array}{l}\text { Learning about other } \\
\text { Cultures/Faiths }\end{array}$} & "Studying diverse interpretations of the same religious practice" & Perspective Taking \\
\hline & "Food and recipes, linked to festivals" & Reducing Anxiety \\
\hline \multirow[t]{2}{*}{$\begin{array}{l}\text { Addressing Inequality from a } \\
\text { Christian Perspective }\end{array}$} & $\begin{array}{l}\text { "Marks gospel units: Jesus' treatment of outcasts and inclusivity and how that } \\
\text { could apply today" }\end{array}$ & Perspective taking \\
\hline & $\begin{array}{l}\text { "Approving the celebration of cultural difference via St. Paul's statements in } \\
\text { Corinthians 1:26-30" }\end{array}$ & Perspective taking \\
\hline \multirow[t]{2}{*}{$\begin{array}{l}\text { Discussion/Dialogue about } \\
\text { Similarities }\end{array}$} & "Highlighting similarities before discussing differences" & $\begin{array}{l}\text { Intergroup commonality and } \\
\text { mutual differentiation }\end{array}$ \\
\hline & "Looking at the similarities of belief and practice for people of different faith" & Intergroup commonality \\
\hline
\end{tabular}


TABLE 2. Researcher Identified themes for practitioner examples for how they embed the contact hypothesis in practice, practitioner examples, and correspondence to research and theory in intergroup relations

\begin{tabular}{|c|c|c|}
\hline Researcher-Identified Themes & Practitioner-provided Example & $\begin{array}{l}\text { Correspondence to Intergroup } \\
\text { Relations Research and Theory }\end{array}$ \\
\hline Encounter & $\begin{array}{l}\text { "Visits to places of worship" } \\
\text { "Use media clips that provoke discussion" }\end{array}$ & Mere Exposure \\
\hline Conversation & $\begin{array}{l}\text { "Talk between minority beliefs and majority belief systems" } \\
\text { "Parents discuss with children" }\end{array}$ & $\begin{array}{l}\text { Discussing Difference but perhaps } \\
\text { in the absence of diverse others }\end{array}$ \\
\hline Interaction & $\begin{array}{l}\text { "Discussion of beliefs between diverse pupil groups" } \\
\text { "When studying a religion ask students to ask a follower of that religion } \\
\text { questions about belief and practice" }\end{array}$ & Meaningful Contact \\
\hline \multirow[t]{3}{*}{$\begin{array}{l}\text { Successful Strategies unrelated } \\
\text { to the contact hypothesis }\end{array}$} & $\begin{array}{l}\text { "Encouraging students to be respectful of and interested in the diverse views } \\
\text { within the teaching group" } \\
\text { "Not tolerating negative behaviour towards other" }\end{array}$ & Modelling Behaviour \\
\hline & $\begin{array}{l}\text { "role play" } \\
\text { "Students are sometimes required to write from a point of view different from } \\
\text { their own" }\end{array}$ & Perspective Taking \\
\hline & $\begin{array}{l}\text { "Having parties celebrating festivals of religions not prominent in school" } \\
\text { "Positively celebrating differences within the group/class/school" }\end{array}$ & $\begin{array}{l}\text { Multicultural/Polycultural } \\
\text { Ideology }\end{array}$ \\
\hline
\end{tabular}

